\title{
VISÃO COMPUTACIONAL: INOVAÇÃO TECNOLÓGICA NA CLASSIFICAÇÃ̃ DE FRUTOS
}

Computational Vision: technological innovation in fruit classification

Visión Computacional: innovación tecnológica en la clasificación de frutos

Warley Gramacho da Silva*1

${ }^{1}$ Docente no Curso de Ciência da Computação e no Mestrado Profissional em Matemática, Universidade Federal do Tocantins. Palmas, Tocantins, Brasil.

*Correspondência: Curso de Ciência da Computação - Universidade Federal do Tocatins, Av. NS 15, 109 Norte, Palmas, Tocantins, Brasil.CEP:77.010-090.e-mail: wgramacho@uft.edu.br

Publicado em 30/12/2018

A produção mundial de frutas, hortaliças e grãos tem apresentado um crescimento contínuo, principalmente considerando o fato de que o Brasil está em escala avançada no âmbito da exportação de matérias-primas agrícolas. O desenvolvimento do setor é notório e a discussão de temas como defesa vegetal, cadeia produtiva, marketing e comercialização, infraestrutura e logística, marco regulatório e pesquisa, desenvolvimento e inovação torna-se frequente. Tal avanço cria competitividade, o que se reflete em maiores exigências por meio dos consumidores quanto a qualidade dos produtos comercializados e maior rigor nos critérios de exportação. Nesse sentido, a indústria alimentícia passou a dedicar mais atenção à inovação tecnológica com foco no desenvolvimento de sistemas de avaliação da qualidade de alimentos que sejam rápidos, confiáveis, minimizem erros inerentes as limitações humanas e maximizem recurso e tempo.

Dentre as inovações tecnológicas que tem sido estudada na área agrícola a visão de computacional destaca-se por constituir-se uma abordagem não destrutiva, promover a objetividade da classificação dos produtos, simular com maior eficácia e em menor tempo o funcionamento da visão humana quanto ao reconhecimento de objetos e padrões. Em geral, as técnicas, utilizam algoritmos para segmentação e extração de características e regiões de interesse, de forma que, definidas essas regiões, seja possível a classificação da imagem de acordo com critérios adotados previamente.

Algumas das técnicas mais utilizadas no âmbito da visão computacional se baseiam unicamente na semelhança dos valores dos pixels expressos em coordenadas tridimensionais para classificação da imagem. Para tanto, é necessário que o sistema saiba diferenciar pixels em regiões diferentes da imagem. Existem também métodos orientados à região, que tomam como critério de classificação diferentes regiões da imagem e suas propriedades. Esse tipo de método utiliza as informações presentes nas vizinhanças de um pixel para sua classificação. Por utilizar as informações presentes na própria imagem como base para segmentação. Um outro fator que o torna esse tipo 
de método atraente para a indústria é a alta adaptação a mudanças externas.

Ainda no contexto da agricultura de precisão destacam-se como inovações tecnológicas veículos terrestres equipados para aquisição de dados de imagem de alta resolução, maximizando a contagem de produtos, o mapeamento de informações do campo e o desenvolvimento de plataformas robóticas agrícolas autônomas para estimar o rendimento de produção e potencializar a colheita automática. As variáveis envolvidas no processo, como os parâmetros de plantio e colheita, que afetam características de cor, textura e consequentemente afetam as respostas de métodos desenvolvidos com base no processamento de imagem, tornam a agricultura de precisão uma área de constante estudo, uma vez que novos métodos são requeridos e buscados para melhoria no processo de detecção e otimização de respostas com eficácia.Apesar da gama de estudos acerca da agricultura de precisão, incluindo a otimização de recursos no campo, a classificação de matérias primas agrícolas quanto a sua qualidade e a minimização de erros humanos, observa-se a ausência de dados e sistemas aplicadas à frutos com particularidades inerentes à sazonalidade, condições de cultivo e outros parâmetros peculiares que podem alterar toda a sistemática proposta. Nesse contexto, as matérias primas do cerrado e amazônicas, por exemplo, são pouco relatadas na literatura no âmbito da inovação tecnologia aplicada a sua cadeia produtiva. Apesar do eminente crescimento de informações no que tange o conhecimento do

potencial funcional, tecnológico e agrícola dessas matérias, sua produção, colheita e classificação é praticamente artesanal, realizada por comunidades com poucos recursos, o que requer a discussão de políticas públicas que contemplem o avanço e o acesso da tecnologia para atender a particularidades de matérias-primas de importância alimentar, social e econômica, mas situadas em regiões geograficamente distantes de pólos industriais de grande porte. 